\title{
O PROCESSO HISTÓRICO DE REGIONALIZAÇÃO ADMINISTRATIVA DO ESTADO DE GOIÁS: EXPERIÊNCIAS DE 1956 A 1989
}

\author{
THE HISTORICAL PROCESS OF ADMINISTRATIVE REGIONALIZATION OF \\ GOIÁS: EXPERIENCES FROM 1956 TO 1989
}

\author{
EL PROCESO HISTÓRICO DE LA REGIONALIZACIÓN ADMINISTRATIVA DE \\ GOIÁS: EXPERIENCIAS DESDE 1956 HASTA 1989
}

\author{
Tathiana Rodrigues Salgado - Universidade Estadual de Goiás - Porangatu - Goiás - Brasil \\ trs.tathi@gmail.com
}

\section{Resumo}

A regionalização do território nacional é uma tendência observada nas práticas políticas brasileiras desde a década de 1940. Como exemplo, podemos citar as primeiras regionalizações elaboradas pelo IBGE, com 0 objetivo de divulgar as estatísticas nacionais ou as regionalizações propostas, a partir da década de 1950, pelas Superintendências de Desenvolvimento (SUDAM, SUDENE, SUDECO). 0 território goiano não escapou a esta tendência, sendo, desde a década de 1950, objeto de diversas regionalizações para fins administrativos e de planejamento. 0 texto que segue busca resgatar e mapear as diferentes experiências de regionalização, para fins de orientação das ações públicas, do território goiano. Adotamos como recorte temporal o período que abrange 0 ano de 1956 ao ano de 1989.

Palavras-chave: regionalização, planejamento, Goiás.

\begin{abstract}
The regionalization of the country is a trend in the Brazilian political practices since the1940s. As an example, we cite the first regionalization prepared by IBGE with the aim of publishing national or regionalization proposals from the 1950s, the Superintendents Development (SUDAM, SUDENE SUDECO). The Goiás territory has not escaped this trend, and since the 1950s, the object of several regionalization for administrative and planning. The text that follows seeks to rescue and map the different experiences of regionalization, for the purpose of guiding public actions of Goiás territory. We take time to cut the period covering the years 1956 to 1989 .
\end{abstract}

Key words: regionalization, planning, Goiás.

\section{Resumem}

La regionalizacióndel país es una tendencia enlasprácticas políticas de Brasil desde la década de 1940. A modo de ejemplo, citamos laregionalización prepara en primer lugar por el IBGE, conel objetivo de lapublicación nacional o laspropuestas de regionalización a partir de la década de 1950, el Superintendente de Desarrollo (SUDAM, SUDENE SUDECO). El territorio de Goiás no ha escapado a esta tendencia, y desde la década de 1950, el objeto de laregionalización de varias administrativas y de planificación. El texto que sigue busca rescatar y mapa de las diferentes experiências de regionalización, conel propósito de orientar las acciones públicas del territorio de Goiás. Nos tomamos el tiempo para reducir el período comprendido entre losaños 1956 a 1989.

Palabras clave: la regionalización, de planificación, Goiás. 


\section{Regionalização como ferramenta para o planejamento}

A regionalização do território nacional é uma tendência observada nas práticas políticas brasileiras desde a década de 1940. O território goiano não escapou a esta tendência, sendo, desde a década de 1950, objeto de diversas divisões regionais realizadas para fins administrativos ou de planejamento. Estas últimas elaboradas, especialmente, com objetivo de orientar a distribuição de investimentos pelo território.

Como já bem documentado na literatura geográfica de Haesbaert (1999), Limonad et al. (2004), Ribeiro (2004), entre outros, são diversas as possibilidades de regionalização de um mesmo território. Dessa forma, os limites, o conteúdo regional, e a própria definição de região, são tão distintos quanto os interesses e as concepções teóricas dos atores envolvidos no processo de regionalização. ${ }^{1}$ Para Limonad et al. (2004, p. 58),

uma regionalização pode fundamentar uma reflexão teórica ou atender às necessidades impostas por uma política setorial, uma prática de planejamento ou por propostas de desenvolvimento regional. As regionalizações possíveis para um mesmo território, espaço social, podem apresentar variações em função da finalidade a que se propõem a atender e poderão estar pautadas em modelos neoclássicos de localização - nunca suficientemente criticada ou esquecida; em matrizes e análises fatoriais, modelo para isto não faltam, ou ainda ter por base concepções variadas desde as regiões funcionais até as regiões polarizadas.

A regionalização, de forma simplificada, pode ser compreendida como processo de diferenciação de áreas, ou seja, de delimitação de regiões, sempre a partir de critérios preestabelecidos pelo ator regionalizador. Assim, observar-se, tal como se referiu Haesbaert (1999, p. 19) que "a princípio qualquer espaço pode ser objeto de regionalizações, dependendo dos objetivos definidos pelo pesquisador."

Porém, cabe, nesta simplificação conceitual, a advertência de Ribeiro (2004). Para a autora, a regionalização mais do que a efetiva delimitação de regiões "inclui o acionamento de ideologias, com apoio, por exemplo, em dados da paisagem, valores culturais compartilhados ou critérios político-científicos que legitimam fronteiras e limites” (Ribeiro, 2004, p. 198). Nesse sentido, a autora destaca que a questão regional pode ser apreendida por duas possibilidades, a construída pela "regionalização 
como fato" que independe da ação hegemônica do presente, e a construída pela "regionalização como ferramenta" desta ação na atual conjuntura. ${ }^{2}$

Segundo a autora, a regionalização como fato depende da reconstrução histórica dos múltiplos processos que movimentaram e limitaram a ação hegemônica no espaço; portanto, nesta acepção, a regionalização requer um esforço de periodização. Ela afirma que

a regionalização como fato encontra-se vinculada aos jogos dinâmicos da disputa de poder, inscritos nas diferentes formas de apropriação (construção e uso) do território. A pesquisa desta regionalização, que depende de articulações espaçotemporais de longo curso, exige, como tantas vezes defendido por Milton Santos, o apoio metodológico da periodização [...] a periodização ao mesmo tempo precede e resulta da interpretação de fatos [...] Portanto, a analise de região correlata à regionalização como fato mobiliza interpretações que tocam, profundamente, as condições historicamente construídas da reprodução social. (Ribeiro, 2004, p. 199)

A regionalização como fato, nos termos apresentados por Ribeiro (2004), é, de acordo com Albuquerque Júnior (2008), embora o autor não use este termo, o que tem faltado aos estudos regionais. De acordo com o autor, é prática comum no discurso historiográfico a região aparecer como um dado apriorístico que não precisa ser em si mesmo pensado ou problematizado, não precisa ser tratado historicamente. Conforme destaca Albuquerque Júnior (2006, p. 63),

a história da região seria o que teria acontecido no interior de seus limites, não a história da constituição destes limites. A história regional seria aquela que aconteceu no interior das fronteiras regionais, não a história dos acontecimentos que produziram essas dadas fronteiras regionais.

Na regionalização como ferramenta, a região aparece como um instrumento para a ação dos atores hegemônicos, negam-se os diversos elementos que caracterizam a existência da região como fato e aplica-se um conjunto de variáveis estabelecidas segundo as finalidades que se deseja alcançar. A regionalização torna-se, dessa forma, uma ferramenta, visto que o ato regionalizador compreende a institucionalização de fronteiras e limites com o objetivo de programar uma determinada ação seja ela analítica, política, econômica ou social. Conforme Ribeiro (2004, p. 196), "a regionalização como ferramenta sempre sustentou a ação hegemônica”. 
Neste texto, será analisada a regionalização como ferramenta para a ação hegemônica. Em nosso caso, ação executada pelo Estado; portanto, o ator regionalizador. A região correlata a esta regionalização é, como destacou Limonad et al. (2004, p. 57), "antes de qualquer coisa uma construção social que atende interesses políticos precisos, mesmo em se tratando de uma região funcional, ou da região natural.”

\section{As regionalizações administrativas do estado de Goiás}

Em Goiás, a primeira regionalização com objetivos administrativos, ou regionalização como ferramenta, para lembrar Ribeiro (2004), foi proposta no Plano de Desenvolvimento Econômico de Goiás (PDGE), documento elaborado durante o governo de Mauro Borges Teixeira, eleito governador em 3 de outubro de 1960, pela coligação PSD-PTN-PTB. Anterior a esta proposta de regionalização, havia uma divisão regional elaborada na década de 1940 pelo Conselho Nacional de Geografia. Esta se baseava em critérios fisiográficos e dividia o estado em 11 zonas: Norte, Taguatinga, Paranã, Planalto, Anápolis, Sul, Alto Tocantins, Goiânia, Médio Araguaia, Sudoeste, Alto Araguaia (Figura 1). Contudo, conforme destacado no PDGE, essa divisão não foi adotada, pois era incompatível com os fins de análise econômica, sendo, portanto, necessário realizar nova regionalização do estado.

A regionalização proposta no PDGE fundamentou-se na diferenciação econômica entre os municípios, fato que resultou na criação de seis regiões: Norte, Planalto, Mato Grosso de Goiás, Goiânia, Estrada de Ferro e Sudoeste (Figura 2). Para delimitar tais regiões, ultilizaram-se critérios de homogeneidade apoiados nas estimativas de renda e produto interno. Cuidou-se de estabelecer coincidência de limites de cada região com os limites municipais.

Valendo-se da regionalização proposta no PDGE, foi identificado o crescimento desequilibrado do território goiano, especialmente no que se refere ao produto interno e à renda, com tendência de concentração na Região Goiânia, conforme podemos notar na Tabela 1. 


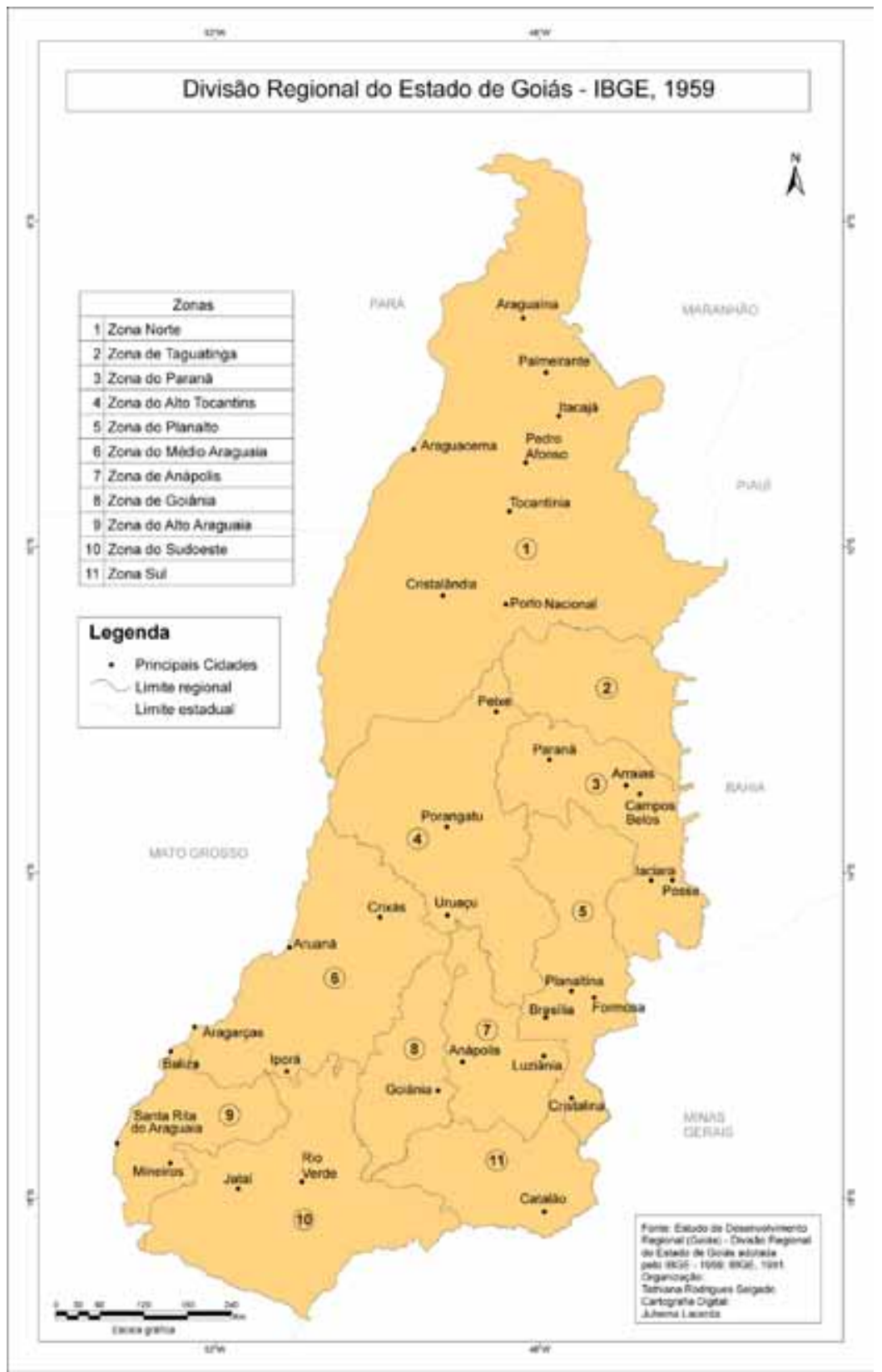

Figura 1 - Divisão Regional do Estado de Goiás adotada pelo IBGE em 1959 


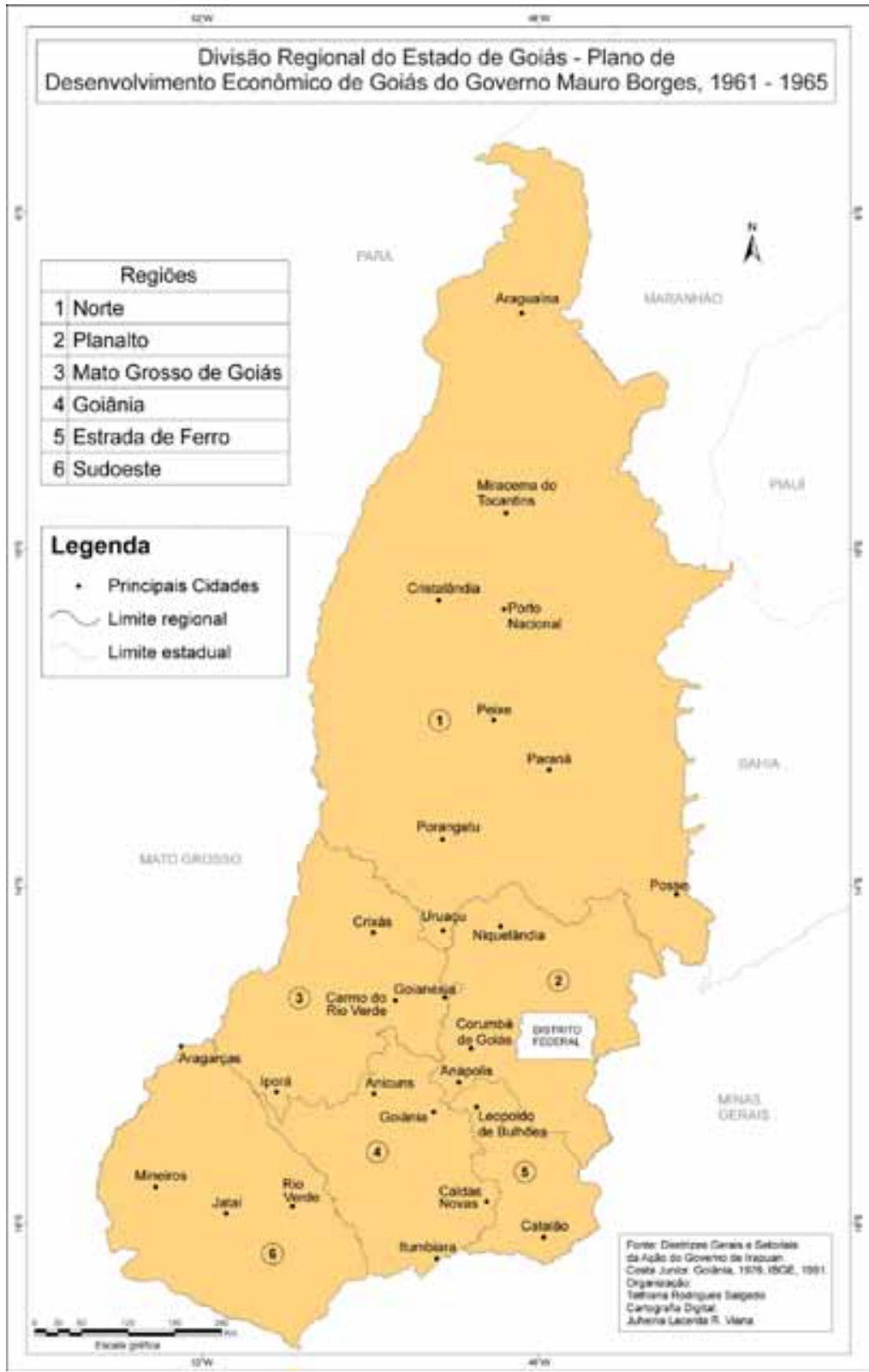

Figura 2 - Divisão Regional do Estado de Goiás - Plano de Desenvolvimento Econômico de Goiás (1961-1965) 
Tabela I - Participação no Produto interno e Renda interna - Goiás - 1955-1958

\begin{tabular}{|l|c|c|c|c|c|c|c|c|c|c|c|c|}
\hline & \multicolumn{2}{|c|}{ Norte } & \multicolumn{2}{c|}{ Planalto } & \multicolumn{2}{c|}{ Mato Grosso } & \multicolumn{2}{c|}{ Goiânia } & \multicolumn{2}{c|}{ Est. Ferro } & \multicolumn{2}{c|}{ Sudoeste } \\
\cline { 2 - 13 } & 1955 & 1958 & 1955 & 1955 & 1955 & 1958 & 1955 & 1958 & 1955 & 1958 & 1955 & 1958 \\
\hline $\begin{array}{l}\text { Produto } \\
\text { Interno* }\end{array}$ & 10,2 & 10,3 & 12,1 & 12,9 & 14,7 & 17 & 43 & 36,1 & 11,4 & 13,3 & 8,7 & 10,3 \\
\hline $\begin{array}{l}\text { Renda } \\
\text { Interna** }\end{array}$ & 937,8 & 1.588 & 1.114 & 1.987 & 1.355 & 2.609 & 3.972 & 5.552 & 1.057 & 2.049 & 799 & 1.578 \\
\hline
\end{tabular}

* Produto Interno em porcentagem

** Renda Interna em Cruzeiro - Cr\$

Fonte: Goiás (1961).

Mas, conforme destacou Arrais (2007), a constatação da desigualdade regional não implicou a busca de uma estratégia de melhor distribuição dos recursos no território. Ao contrário, os investimentos do governo federal e do estadual, especialmente com programas de colonização e infraestrutura, privilegiaram as regióes de Goiânia e Mato Grosso, fato claramente exposto no PDGE, conforme podemos notar no trecho a seguir:

Aceitando-se a ideia de crescimento desequilibrado e dos pontos de difusão do crescimento econômico, as tabelas indicativas da distribuição percentual do produto bruto de Goiás, segundo setores de origem e por regiões, parecem indicar a conveniência da concentração dos investimentos públicos em capital social na zona de Goiânia, a fim de solidificar sua infraestrutura e os investimentos agrícolas na região "Mato Grosso" de Goiás, cuja emergência, como polo de crescimento, leva a crer que se trate de uma zona pioneira para onde, caracteristicamente, se desloca a fronteira de investimento, através da utilização de novos termos de cultura e pastagem. (Goiás, 1961, p. 126-127)

Em virtude do Golpe Militar de 1964, Mauro Borges é destituído do cargo em $1^{\circ}$ de janeiro do mesmo ano, e em seu lugar é nomeado um Interventor Federal, Coronel Carlos de Meira Mattos, que assume o Executivo de Goiás de 26/11/1964 a 23/01/1965 e, em seguida, assume o poder Emílio Rodrigues Ribas Júnior, com o mandato de 23/1/1965 a 31/1/1966. Nesse curto espaço de tempo, pouco mais de um ano, não há registros, em obras goianas, de elaboração de novas regionalizações para fins administrativos.

Em 23 de abril de 1968, foi submetido à Assembleia Legislativa de Goiás, pelo governador Otávio Lage, o segundo plano de governo elaborado no Estado, o Plano de Ação do Governo de Otávio Lage (PAG). No PAG, para construir o diagnóstico do desenvolvimento estadual, o estado de Goiás foi dividido em 16 regiões: Extremo Norte, Araguaia, Nordeste, Ba- 
nanal, Palma, Crixá-Assú, Tocantizinho, Leste, Rio Vermelho, Mato Grosso de Goiás, Planalto, Alto Araguaia, Sudoeste, Meia Ponte, Estrada de Ferro e Paranaíba (Figura 3). Conforme é apresentado no PAG:

A fim de se estudar o desenvolvimento regional a partir de polos de desenvolvimento, organizou a Secretaria do Planejamento em cooperação com o Conselho Nacional de Geografia, o agrupamento dos municípios do Estado em regiões homogêneas. (Goiás, 1967, p. 63)

Conforme apresentado no PAG, constituiam-se como regiões um grupo de municípios contíguos, com índices de progresso socioecônomico semelhante e polarizado em um mesmo centro urbano.

Cunha (2006) registra que o plano seguinte foi elaborado em 1971, no governo de Leonino Caiado. Contudo, na pesquisa documental, não foi encontrada nos órgãos de governo - Secretaria de Planejamento (SEPLAN) e Instituto Histórico e Geográfico de Goiás (IHGG) - cópia completa, ou referência à lei de criação do plano. Portanto, para o período de 1971 a 1975 não há registro de nova regionalização para o estado.

O plano seguinte foi publicado em 1975, durante o governo de Irapuan Costa Junior, sendo denominado Diretrizes Gerais e Setoriais da Ação do Governo Irapuan Costa Júnior (DGSAG). O documento apresentou as intenções de ação para o período de março de 1975 a março de 1979. A adoção de uma nova regionalização do território foi justificada como necessária à melhor eficácia dos diagnósticos e das ações do poder executivo. Vejamos, por exemplo, como o tema foi destacado no plano DGSAG:

Para efeito de diagnóstico do desenvolvimento regional, o estado de Goiás foi dividido em sete regiões: Norte, Noroeste, Nordeste, Leste, Centro-Oeste, Sul e Sudeste. Estudos realizados comprovaram a existência de desníveis regionais acentuados. (Goiás, 1976, p. 61)

Nas Diretrizes Gerais e Setoriais da Ação do Governo (DGSAG), elaboradas no mandato de Irapuan Costa Júnior, para efeito de diagnótico do desenvolvimento regional, o estado de Goiás foi regionalizado em sete regiões: Norte, Noroeste, Nordeste, Leste, Centro-Oeste, Sudeste e Sul (Figura 4). 


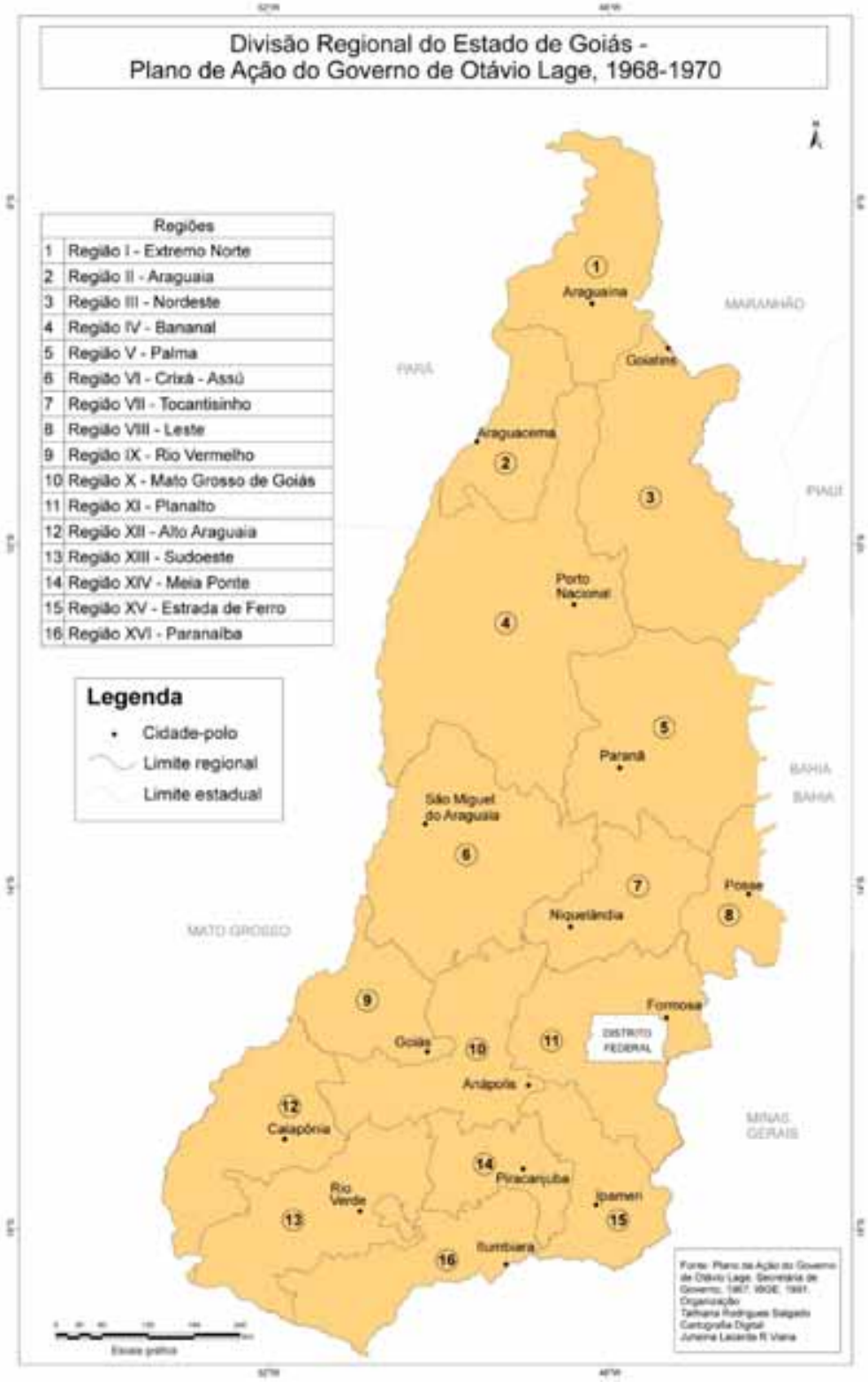

Figura 3 - Divisão Regional do Estado de Goiás - Plano de Ação do Governo de Otávio Lage (1968-1970) 
Os estudos apresentados no diagnóstico das DGSAG comprovaram a existência de desníveis regionais acentuados e dada a extensão das regiões de tal desnível são identificados também em escala intrarregional. De acordo com o apresentado nas DGSAG,

verificou-se que tais desníveis caracterizavam-se principalmente por uma economia ora acelerada, ora estacionária e até mesmo involutiva e com estágios diferenciados de desenvolvimento econômico e social. (Goiás, 1976, p. 61)

Associado a este ponto, a estrátegia de ação espacial do plano é voltada para diminuir o desequilíbrio existente entre as várias regiões em que foi dividido o Estado. Os projetos de intervenção das DGSAG foram estruturados a partir do conceito dos "Polos de Crescimento e Desenvolvimento", desenvolvido por François Perroux. ${ }^{3}$ Portanto, a aplicação dos investimentos foi direcionada para polos prioritários de desenvolvimento, que se contituíram em áreas-programas, cada área formada por um polígono compreendido pela interligação das principais cidades de cada região.

Conforme é apresentado no plano DGSAG, com os investimentos em polos específicos buscava-se, por meio indutor, irradiar os benefícios às demais cidades das regiões. A estratégia espacial era levar até aqueles polos determinados serviços existentes somente nas grandes cidades, de modo a possibilitar a radiação, em cada região, de seus próprios residentes e de mais um programado fluxo migratório, buscando um alívio das pressões de demanda sobre os serviços industriais e sociais básicos, nos grandes centros urbanos. Como podemos verificar, as DGSAG constituem o primeiro plano estadual com uma explícita política territorial.

A regionalização seguinte, baseada em indicadores econômicos, porém com metodologia pouco explícita no plano, foi realizada no governo de Iris Rezende Machado (1984-1987); neste caso, o estado foi regionalizado em 20 regiões (Figura 5). 


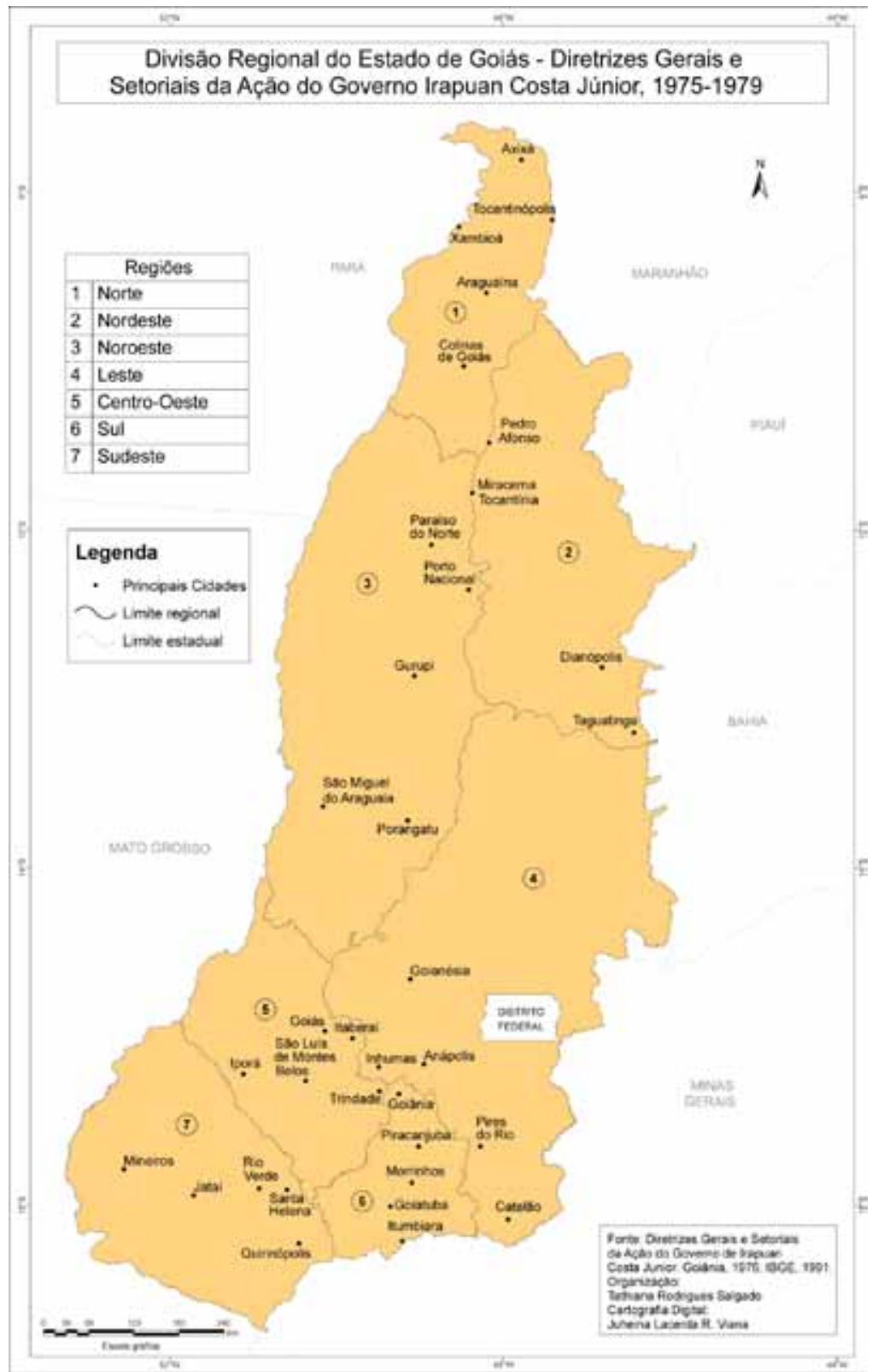

Figura 4 - Divisão Regional do Estado de Goiás - Diretrizes Gerais e Setoriais da Ação do Governo de Irapuan Costa Junior (1975-1979) 


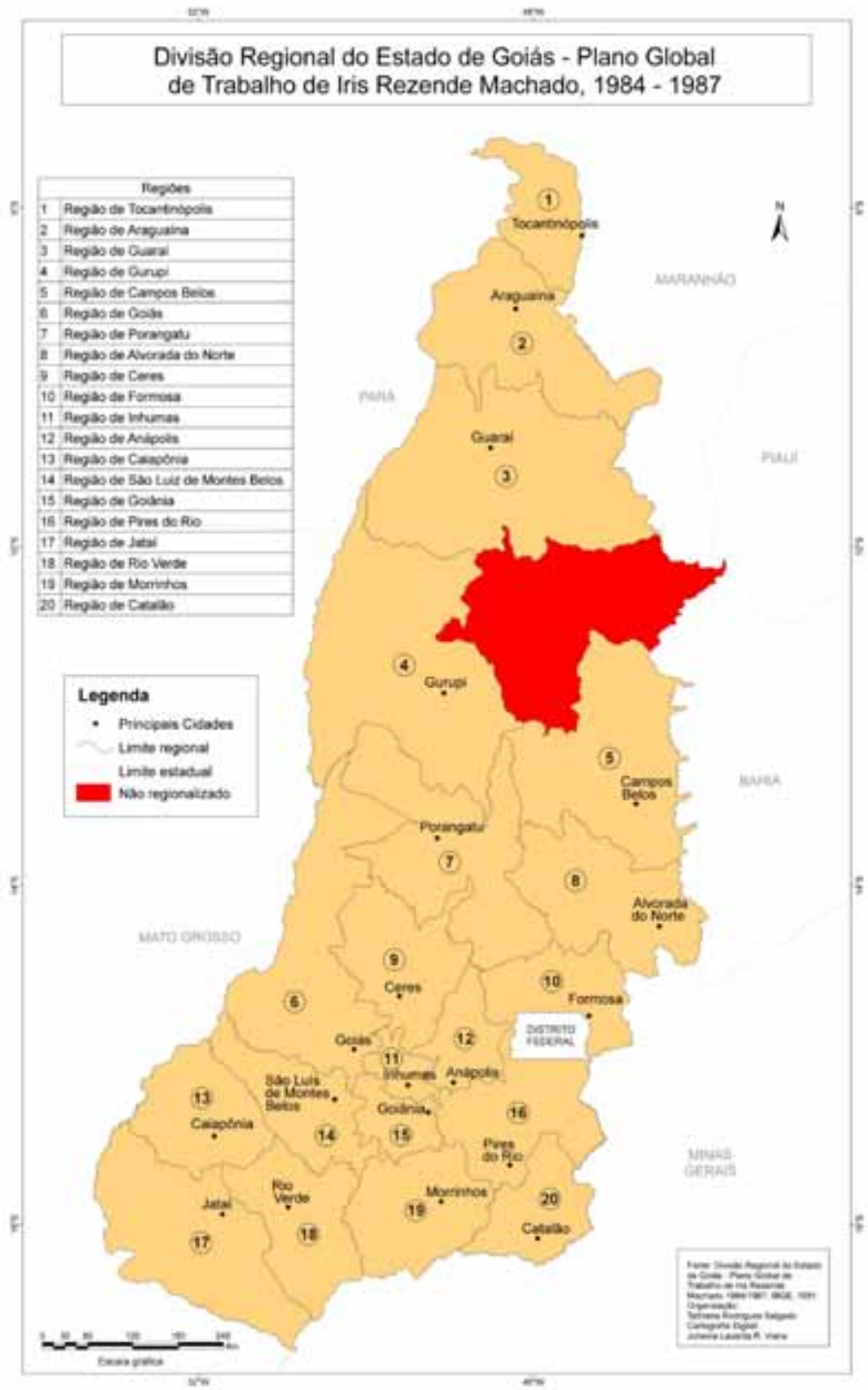

Figura 5 - Divisão Regional do Estado de Goiás - Plano Global de Trabalho de Iris Rezende Machado 1984-1987 
Artigo

\section{Considerações finais}

O objetivo do texto foi apresentar as experiências de regionalização do território goiano dentro do recorte temporal de 1956 a 1987. Pode-se destacar, após a análise destas experiências, que estas regionalizações:

1) revelaram um território marcado pela desigualdade regional;

2) buscaram atender às necessidades de identificação de pontos de germinação do crescimento econômico;

3) como estratégia de desenvolvimento, adotou-se a concentração de investimentos nestes pontos, que, na concepção dos planos de governo, funcionariam como irradiadores de desenvolvimento para os municípios circunvizinhos.

Mas, como já bem documentado nos estudos sobre desenvolvimento regional do estado de Goiás - Arrais (2007), Estevam (1998), Silva (2007) - os esforços estatais, ao capitalizarem áreas historicamente mais desenvolvidas, reforçaram as desigualdades regionais em Goiás.

Haesbaert (1999), ao analisar o fundamento teórico da diversidade territorial, destaca que a diversidade regional se manifesta, em geral, sob duas grandes formas: a diferença de natureza qualitativa, "em geral de base local e sem correlação obrigatória com realidades geográficas em outras escalas", e a diferença de grau ou intensidade, "mais quantitativa que vincula os espaços em distintas escalas" (1999, p. 24). A desigualdade regional, apresentada nas regionalizações estaduais, está circunscrita à segunda forma, já que elas, elaboradas a partir de parâmetros econômicos, revelam que o desenvolvimento geográfico, sob o modo de produção capitalista, tem um caráter altamente seletivo e excludente, conforme destaca o autor.

Portanto, a partir das regionalizações apresentadas, a região de planejamento, enquanto conceito, pode ser definido, no caso da experiência goiana de regionalização, como um recorte espacial contíguo, delimitado em virtude de interesses específicos, não homogêneo, institucionalizado, mas sem autonomia administrativa, destinado a orientar as ações de um governo. Estas com a finalidade de promover determinado modelo de desenvolvimento. Nessa perspectiva, trata-se, segundo Haesbaert (2010), de uma noção mais normativa de região; uma noção

não tanto - ou não apenas - preocupada em reconhecer "o que é" efetivamente a região enquanto realidade empírica ou em desdobrá- 
la e avaliá-la enquanto instrumento de analítico, mas em propor ações, caminhos, "indicar um futuro" ou um devir (delineando novas conexões) das configurações regionais, de modo a adequálas a determinados propósitos políticos e econômicos, vinculandose portanto, de alguma forma, também ao chamado planejamento regional.

Estas regionalizações, teoricamente, deveriam orientar espacialmente o diagnóstico, a elaboração e a distribuição dos projetos e investimentos estatais do Estado de Goiás. Estes, distribuídos de forma a propiciar o desenvolvimento harmônico e equilibrado do território, minimizando as históricas desigualdades regionais do estado de Goiás.

\section{Notas}

1. Sobre a região, muito já foi escrito, aqui destacamos os trabalhos de Kayser (1980), Correa (1986), Lima (2002), Lencioni (1999) e Arrais (2007) Gomes (1995), Haesbaert (2010), fato que nos desobriga de refazer neste trabalho uma reconstrução histórica sobre o conceito de região.

2. Para Ribeiro (2004), ação hegemônica é aquela conduzida pelas forças econômicas e políticas, que dominam o território brasileiro, expressivas da aliança entre agentes externos e internos e condutores de numerosas e difusas ações subalternas ou subalternizadas. Ainda de acordo com a autora, na contraface dos desígnios da ação hegemônica, temos tanto as formas de resistência, por vezes em confronto apenas com agentes secundários, como dinâmicas sociais que escapam aos mecanismos de controle que garantem a expansão da territorialidade dominante.

3. De acordo com Perroux (1978, p. 100), "o fato rudimentar mais consistente é este: o crescimento não surge em toda a parte ao mesmo tempo; manifesta-se com intensidades variáveis, em pontos ou polos de crescimento; propaga-se, segundo vias diferentes e com efeitos finais variáveis, no conjunto da economia”.

\section{Referências}

ALBUQUERQUE JÚNIOR, Durval Muniz de. O objeto em fuga: algumas reflexões em torno do conceito de região. Revista Fronteiras, Dourados, MS, v. 10, p. 55-67, jan./jun. 2008.

ARRAIS, Tadeu Alencar. Planejamento e desenvolvimento regional: a intervenção governamental e a problemática regional em Goiás. Mercator - Revista de Geografia da UFC, ano 6, n. 12, 2007.

CORREA, R. L. Região e organização espacial. São Paulo: Ática, 1986.

CUNHA, Sulamita de Aquino P. M. Planejamento Governamental em Goiás. In: Economia e desenvolvimento. Governo de Goiás, SEPLAN, 2006. 
ESTEVAM, L. O tempo da transformação: estrutura e dinâmica da formação econômica de Goiás. Goiânia: Ed. do Autor, 1998. 276 p.

GOIÁS. Plano de Desenvolvimento Econômico de Goiás - 1961-1965. v. 1 e 2. Goiânia: Secretaria de Governo, 1961.

GOIÁS. (Constituição de 1967) Constituição do Estado de Goiás. 1967.

GOIÁS. Plano de Ação do Governo de Otávio Lage. Goiânia: 1967.

GOIÁS. Diretrizes gerais e setoriais da ação do Governo de Irapuan Costa Junior. Goiânia: Oriente, 1976.

GOIÁS. Plano Global de Trabalho do Governo de Iris Rezende. Goiânia: CERNE. 1984.

GOIÁS. Constituição do Estado de Goiás. Goiás. 1989.

GOMES, Paulo César da Costa. O conceito de região e sua discussão. In: CASTRO, I. E. et al. (Orgs.). Geografia: conceitos e temas. Rio de Janeiro: Bertrand Brasil, 1995.

HAESBAERT, Rogério. Região, diversidade territorial e globalização. Niterói: DEGEO/UFF, 1999.

HAESBAERT, Rogério. Regional-Global: dilemas da região e da regionalização na geografia contemporânea. Rio de Janeiro: Bertrand Brasil, 2010.

KAYSER, B. A região como objeto de estudo da geografia. In: GEORGE, P. et al. A geografia ativa. São Paulo/Rio de Janeiro: Difusão Editorial, 1980.

LENCIONI, Sandra. Região e geografia. 1. ed. São Paulo: EDUSP, 1999.

LIMA, Gisélia Carvalho. Região: a evolução de uma categoria de análise da geografia. Boletim Goiano de Geografia, v. 22, n. 1, jan./jun. 2002.

LIMONAD, E.; HAESBAERT; MOREIRA, R. (Orgs.). Brasil século XXI - por uma nova regionalização? Agentes, processos e escalas. São Paulo: Max Limonad, 2004.

PERROUX, F. O conceito de polo de desenvolvimento. Urbanização e regionalização. Rio de Janeiro: IBGE, 1978.

RIBEIRO, Ana Clara Torres. Regionalização: fato e ferramenta. In: LIMONAD, E.; HAESBAERT, R.; MOREIRA, R. (Org.). Brasil século XXI - por uma nova regionalização? Agentes, processos e escalas. Rio de Janeiro: Marx Limonad, 2004.

SILVA, Eduardo R. da. A economia goiana no contexto nacional: 1970-2000. Goiânia: Ed. da UCG, 2007.

Tathiana Rodrigues Salgado - Mestre em Geografia pela Universidade Federal de Goiás e professora adjunta da Universidade Estadual de Goiás. 